\title{
Las actividades complementarias de las explotaciones agrícolas peruanas
}

Les activités complémentaires des exploitations agricoles péruviennes

Complementary activities in Peruvian farming

\section{Pascale Phélinas}

\section{(2) OpenEdition}

\section{Journals}

Edición electrónica

URL: http://journals.openedition.org/bifea/6844

DOI: $10.4000 /$ bifea.6844

ISSN: 2076-5827

\section{Editor}

Institut Français d'Études Andines

Edición impresa

Fecha de publicación: 1 diciembre 2002

Paginación: 725-750

ISSN: 0303-7495

Referencia electrónica

Pascale Phélinas, "Las actividades complementarias de las explotaciones agrícolas peruanas », Bulletin de l'Institut français d'études andines [En línea], 31 (3) | 2002, Publicado el 08 diciembre 2002, consultado el 07 diciembre 2020. URL : http://journals.openedition.org/bifea/6844 ; DOI : https:// doi.org/10.4000/bifea.6844

\section{(c) $98 \%$}

Les contenus du Bulletin de l'Institut français d'études andines sont mis à disposition selon les termes de la licence Creative Commons Attribution - Pas d'Utilisation Commerciale - Pas de Modification 4.0 International. 


\title{
LAS ACTIVIDADES COMPLEMENTARIAS DE LAS EXPLOTACIONES AGRÍCOLAS PERUANAS
}

\author{
Pascale PHÉLINAS*
}

\section{Resumen}

La diversificación de las fuentes de ingresos de las explotaciones agrícolas es un asunto crucial para el bienestar de las poblaciones rurales. De hecho, en el medio rural, todo trabajo adicional en actividades distintas a las directamente relacionadas con la explotación agrícola puede contribuir al aumento de los ingresos, aun en forma modesta. Este trabajo muestra que, pese a su potencial en términos de generación de empleos e ingresos, las actividades adicionales de las explotaciones agrícolas constituyen todavía un campo de la economía rural poco entendido. Esta debilidad resulta a la vez de la heterogeneidad de dichas actividades, lo que genera mucha confusión conceptual, y de lagunas en las estadísticas nacionales disponibles, las cuales no registran esas actividades de manera adecuada. A pesar de estas dificultades, el presente trabajo busca dar una idea de la importancia y características de las actividades complementarias de las explotaciones agrícolas peruanas. Surgen cuatro conclusiones principales del conjunto de resultados presentados: la subestimación indudable de esas actividades y de los ingresos resultantes; la parte importante de la agricultura en el conjunto de las actividades complementarias, la concentración de dichas actividades en dos o tres sectores y la estabilidad relativa de su distribución en el tiempo y espacio según los sectores; y la división laboral marcada entre hombres y mujeres.

Palabras claves: Perú, economñia rural, diversificación, analisis estadística.

\section{LES ACTIVITÉS COMPLÉMENTAIRES DES EXPLOITATIONS AGRICOLES PÉRUVIENNES}

\section{Résumé}

La diversification des sources de revenu des exploitations agricoles est une question cruciale pour le bien être des populations rurales. En effet, toute utilisation supplémentaire du travail en milieu rural pour des activités autres que celles directement liées à l'exploitation agricole peut contribuer à augmenter les revenus, même modestement. Cet article montre que malgré le potentiel que représentent les activités complémentaires des exploitations agricoles tant en termes de création d'emplois que de revenus, elles sont encore un domaine peu compris de l'économie rurale. Cette faiblesse provient à la fois de l'hétérogénéité de ces activités qui est à la source de nombreuses confusions conceptuelles et des lacunes des statistiques nationales disponibles qui n'enregistrent pas ces activités de manière adéquate. En dépit de ces difficultés,

\footnotetext{
*IRD, casilla 18-1209, Lima 18 Perú. E-mail: p.phelinas@terra.com.pe
} 
cet article tente de donner un aperçu de l'importance et des caractéristiques des activités complémentaires des exploitations agricoles péruviennes. Quatre conclusions principales émergent de l'ensemble des résultats présentés : la sous-estimation indubitable de ces activités donc des revenus qui en découlent; la part significative qu'occupe l'agriculture dans l'ensemble des activités complémentaires, la concentration de ces activités dans deux ou trois secteurs, la relative stabilité de leur distribution selon les secteurs dans le temps et dans l'espace, une division du travail assez marquée entre les hommes et les femmes.

Mots-clés : Pérou, économie rurale, diversification, analyse statistique.

\title{
COMPLEMENTARY ACTIVITIES IN PERUVIAN FARMING
}

\begin{abstract}
Diversifying sources of farming income is a crucial issue for the welfare of rural populations. Indeed, in rural areas, any additional work dedicated to activities that are not directly related to farming may contribute to rises in income, albeit modest. This paper demonstrates that, despite the potential of activities that complement farming, both in terms of job creation and income generation, there continues to be little understanding of this area of rural economy. This weakness is due to the heterogeneity of such activities, which produces a great deal of conceptual confusion, and to the shortcomings of national statistics, which do not register these activities properly. In spite of these difficulties, this paper seeks to provide an overview of the importance and characteristics of the activities that complement farming in Peru. Four main conclusions emerge from the results presented here: the unquestionable underestimation of these activities and the income they generate; the significant proportion of agriculture in complementary activities; the concentration of these activities in two or three sectors and the relative stability of their distribution in time and space, according to sectors; and a rather marked division of labor between men and women.
\end{abstract}

Key words: Peru, rural economy, diversification, tatistic analysis.

\section{INTRODUCCIÓN}

Las teorías del desarrollo han dedicado siempre una atención considerable a las transferencias intersectoriales de recursos de la agricultura hacia la industria en el curso del proceso de desarrollo económico. Durante varias décadas, después de los trabajos de Arthur Lewis (1954), la doctrina económica ha estado marcada por los modelos duales. Partiendo de la hipótesis de que en los PVD la población es mucha en relación a los recursos naturales, estos modelos postulan la existencia de una desocupación llamada oculta en el medio rural, que se manifiesta por un bajo número de horas trabajadas y por una productividad marginal del trabajo cercana o igual a cero. En este contexto, existiría en el sector agrícola una oferta ilimitada de mano de obra, cuya transferencia al sector industrial debería traducirse por un aumento de crecimiento económico.

Sin embargo, esta visión convencional del desarrollo económico supone que la población y las actividades están separadas en compartimentos estancos. Lo rural se opone entonces a lo urbano, la agricultura se opone a la industria y el desarrollo económico está asociado con un desplazamiento de mano de obra entre los sectores y con la urbanización. En realidad, el desarrollo económico está casi siempre marcado por un proceso de diversificación de las actividades en el medio rural. Este proceso, 
ignorado por mucho tiempo, ha recibido en el curso de la última década una atención acrecentada tanto por parte de los proveedores de fondos como de la comunidad científica. Este interés proviene a la vez de la importancia de las actividades complementarias de las explotaciones agrícolas (1) en el tiempo total de trabajo dedicado a las actividades productivas o incluso en el ingreso total de los hogares agrícolas, y de los efectos benéficos que se esperan del desarrollo de estas actividades: reducción de la pobreza y de la desigualdad de ingresos, desarrollo de un empresariado local, absorción de la mano de obra rural "excedentaria", disminución del éxodo rural, financiamiento de la inversión agrícola, etc.

El Perú es un país en el que el 54,8\% de las personas vive por debajo del límite de pobreza y donde las desigualdades de ingresos se encuentran entre las más altas de América Latina (Herrera, 2002). La pobreza, como en muchos de los PVD, está concentrada en el medio rural, particularmente en las zonas de la Sierra. Ahora bien, la visión dominante sobre las posibilidades de mejoría de los ingresos agrícolas es muy pesimista. Este pesimismo se basa en la pobreza de los recursos naturales, en el rigor del clima, unido a la altura, y en una estructura agraria compuesta de unidades agropecuarias de pequeño tamaño. La adopción de técnicas de producción intensivas sería difícil, porque la tecnología moderna no sería apropiada para las condiciones ecológicas y económicas de la producción andina (Gonzáles et al., 1987; Gonzáles, 1994).

Aunque la cuestión de la modernización de la agricultura peruana es objeto de un debate (Cotlear, 1989), las escasas perspectivas de mejoría de la productividad de la agricultura han desplazado la atención hacia la capacidad del sector no agrícola para proveer empleos e ingresos a los miembros de las explotaciones agrícolas, ya sea en concepto de ingreso principal o secundario. El desarrollo de actividades de diversificación aparece así como uno de los medios eficaces de lucha contra la pobreza.

El objetivo de este artículo es mostrar que a pesar de la atención reciente que se presta a las actividades complementarias de las explotaciones agrícolas y el potencial que representan en términos de creación de empleos y de ingresos, éstas constituyen todavía un campo poco comprendido de la economía rural. Esto proviene a la vez de la heterogeneidad de estas actividades y, hasta hace muy poco, de la falta de atención teórica y empírica. Se subrayará en un primer momento que la gran heterogeneidad de estas actividades es la causa de muchas confusiones conceptuales. En un segundo momento se mostrará que las estadísticas nacionales disponibles no registran estas actividades de manera adecuada. Finalmente, se tratará de reunir la información pertinente que permita describir la utilización de la mano de obra de las explotaciones agrícolas.

(1) Es difícil encontrar un término satisfactorio y conciso para nombrar y describir el conjunto de actividades que desarrollan los miembros de las explotaciones rurales para diversificar sus fuentes de ingresos fuera de la explotación agrícola. El término de actividad secundaria, que tenía nuestra preferencia, ha sido dejado de lado porque ya se utiliza en la mayoría de estudios estadísticos para definir la actividad que ocupa el mayor tiempo productivo después de la actividad principal. Para evitar cualquier confusión, hemos escogido el término de actividad complementaria. 


\section{LA HETEROGENEIDAD DE LAS ACTIVIDADES COMPLEMENTARIAS, CAUSA DE CONFUSIÓN CONCEPTUAL}

La diversificación de las actividades (o pluriactividad) puede definirse simplemente como la obtención de un ingreso de más de una actividad económica. El tiempo productivo de un individuo puede utilizarse entonces de varias maneras. Las diferentes opciones son: la unidad productiva agrícola, las actividades no agrícolas realizadas en el mismo lugar, el empleo en el mercado de trabajo agrícola y/o no agrícola. Esta diversidad de posibilidades lleva a menudo a análisis parciales de la pluriactividad y a numerosas confusiones en relación con las actividades que deben ser tomadas en cuenta o no.

Las diferentes opciones mencionadas anteriormente se estudian por lo general por separado en la literatura económica y según preocupaciones diferentes. La categoría actividad fuera de la explotación (off-farm) se refiere generalmente a la actividad ejercida fuera de la explotación agrícola y excluye por lo tanto todas las actividades no agrícolas desarrolladas en el lugar mismo. Los estudios que recurren a este concepto tienen como objetivo el análisis del mercado de trabajo. La categoría actividad no agrícola (non-farm) agrupa todas las actividades no agrícolas, sin diferenciar necesariamente la actividad asalariada del autoempleo, y excluye las actividades agrícolas asalariadas. El objeto es, por lo general, el estudio de las perspectivas de industrialización rural. Finalmente, la categoría migración agrupa las actividades desarrolladas lejos de la explotación agrícola. Las preocupaciones se centran generalmente alrededor de la tasa de urbanización y de los efectos de los envíos de fondos por parte de los migrantes.

Considerando las interacciones complejas que existen entre empleo en la explotación agrícola y empleo fuera de la explotación agrícola, entre empleo agrícola y no agrícola, la pluriactividad de los hogares agrícolas debe ser considerada teniendo en cuenta todos sus componentes. Nuestra concepción de actividad complementaria se encuentra en la confluencia de los tres conceptos mencionados anteriormente. Se entiende por actividad complementaria el conjunto de ocupaciones dirigidas a desarrollar fuentes de ingresos diferentes a las provenientes de la explotación agrícola propia, ya sea como ingreso principal o secundario. Este conjunto comprende entonces las actividades que tienen lugar fuera de la explotación, cualquiera que sea el sector de actividad (agrícola o no agrícola) y las actividades no agrícolas que tienen lugar en la explotación .

Por las necesidades del análisis, es interesante diferenciar varias categorías de ocupación complementaria cruzando tres criterios pertinentes: el sector de la actividad escogida (agrícola/no agrícola), el estatus en la actividad (autoempleo/trabajo asalariado), la localización del empleo (rural local/urbano alejado). Se obtienen así 5 tipos diferentes de ocupación: el autoempleo en el sector no agrícola, el empleo en el mercado de trabajo agrícola local, el empleo en el mercado de trabajo no agrícola local, el empleo agrícola y no agrícola en el mercado de la migración. Esta clasificación no es arbitraria; hace referencia a diferentes tipos de empleos cuyas particularidades, como la estacionalidad, la localización, las remuneraciones, las barreras para el ingreso etc. pueden variar considerablemente y requerir en cambio características particulares de los trabajadores 
(edad, sexo, educación), o de las explotaciones (localización, tamaño). En ese caso, los efectos de selección que se derivan de todo ello pueden resultar en una segmentación del mercado de trabajo.

Finalmente, la diversificación de las actividades o de las fuentes de ingresos puede organizarse según varias modalidades concretas. Una explotación puede incrementar la diversidad de sus fuentes de ingresos aumentando el número de trabajadores que ejercen una actividad complementaria y/o aumentando el número de actividades complementarias ejercidas por cada uno de los trabajadores. Una explotación puede tener así a uno solo, a varios o a todos sus miembros ocupados en actividades complementarias. Del mismo modo, cada individuo puede ejercer una o varias actividades complementarias. Estas actividades pueden ser realizadas al mismo tiempo que la actividad agrícola, o al contrario en alternancia con la actividad agrícola. Un individuo puede así cambiar de ocupación y/o de sector de actividad durante el año agrícola, o ejercer varias actividades al mismo tiempo, en diferentes sectores, en un período dado.

Estas son algunas precisiones conceptuales que permiten identificar el conjunto de variables que habría que medir de manera apropiada para dar cuenta de la diversidad y de la complejidad del conjunto de "actividades complementarias". Estas variables son: el número total de ocupaciones diferentes ejercidas por cada miembro activo de la explotación en el curso de un año agrícola, el sector de actividad de cada ocupación, su localización, el calendario preciso de cada una de las diferentes ocupaciones, y finalmente el estatus del trabajador en cada ocupación. Ahora bien, las estadísticas nacionales disponibles no permiten obtener el conjunto de las informaciones sobre las variables en cuestión.

\section{LA INSUFICIENCIA DE LAS ESTADÍSTICAS NACIONALES}

En el Perú, por lo general, las estadísticas oficiales no toman bien en cuenta las actividades complementarias de las familias agrícolas debido a las metodologías de encuesta. Se encuentran elementos sobre las actividades de los miembros de las explotaciones agrícolas en diversas fuentes: el último censo agrícola, que data de 1994, las encuestas sobre el nivel de vida de las familias realizadas por el Instituto CUÁNTO bajo la égida del Banco Mundial en 1985, 1991, 1994, 1997 y 2000, y un número significativo de encuestas sobre las familias realizadas regularmente por el Instituto Nacional de Estadística e Informática (INEI), cuyo objetivo es variable, y que incluyen módulos más o menos detallados sobre el empleo de los ingresos.

En el cuadro 1 se han resumido las características de estas diferentes encuestas. Se mostrará a lo largo de la exposición que estas fuentes existentes, aunque numerosas y con una gran riqueza de información, no permiten sin embargo evaluar de manera satisfactoria la importancia y la naturaleza de las actividades complementarias de las explotaciones agrícolas, ni apreciar el dinamismo del mercado de trabajo en el medio rural, y esto por varias razones. 


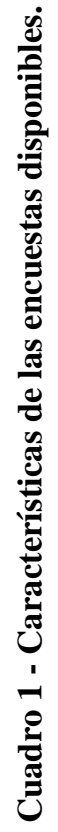

\begin{tabular}{|c|c|c|c|c|c|c|c|c|c|}
\hline 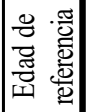 & 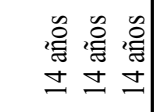 & 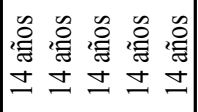 & 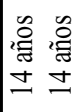 & 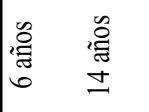 & $\begin{array}{l}\text { 怘 } \\
\text { さ્త }\end{array}$ & 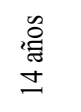 & 章 & 兽 & 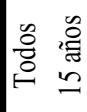 \\
\hline 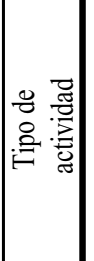 & 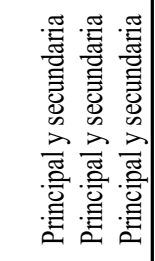 & 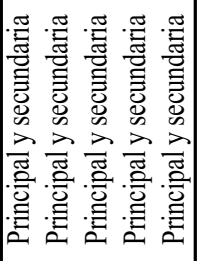 & 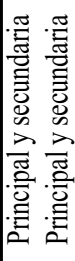 & 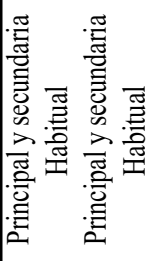 & 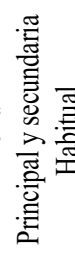 & 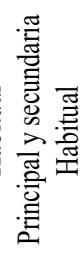 & 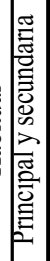 & 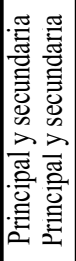 & 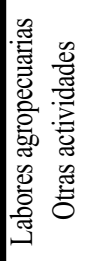 \\
\hline 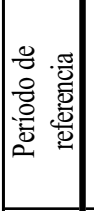 & 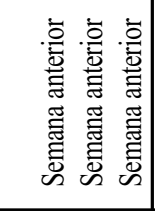 & 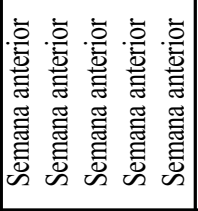 & 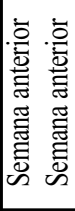 & 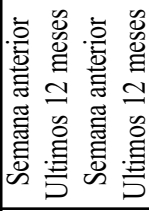 & 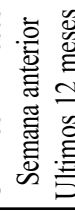 & 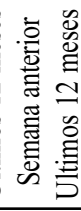 & 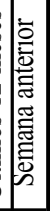 & 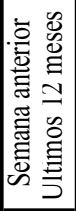 & 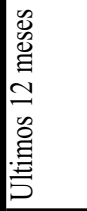 \\
\hline 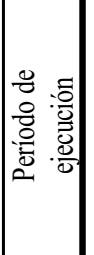 & 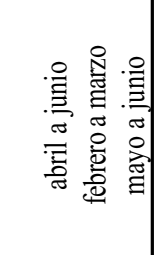 & 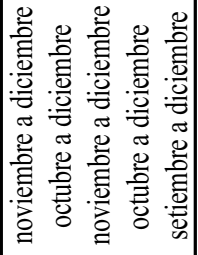 & 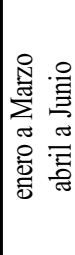 & 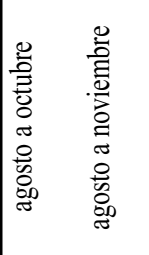 & 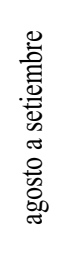 & 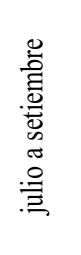 & 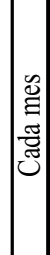 & 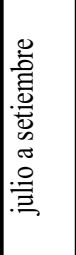 & \\
\hline 妾 & 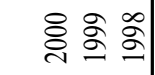 & 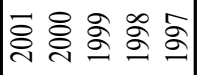 & চ্ণি & 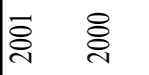 & ڤे & $\stackrel{\infty}{\sigma}$ & & बू & बे \\
\hline 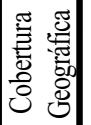 & 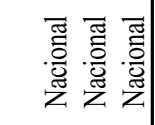 & 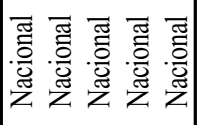 & 营营 & 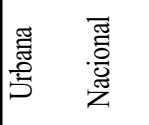 & 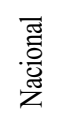 & 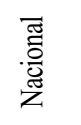 & 节 & 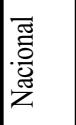 & 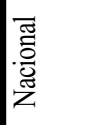 \\
\hline 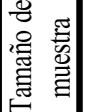 & ્ㅗㅀ윯에 & 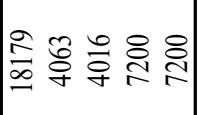 & 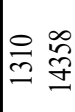 & 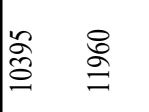 & 옹 & $\frac{2}{2}$ & 을 & స్ర్లి & \\
\hline & 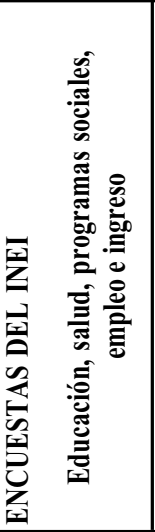 & 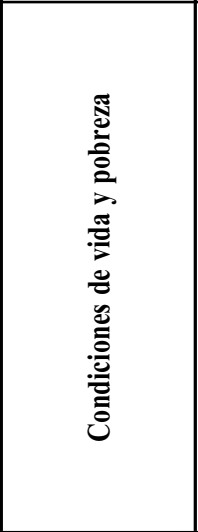 & 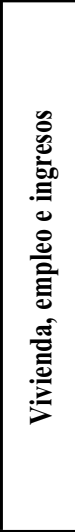 & 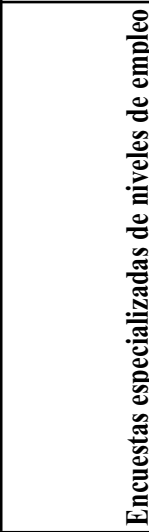 & & &  & 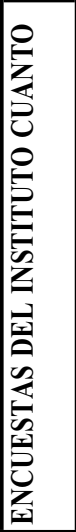 & 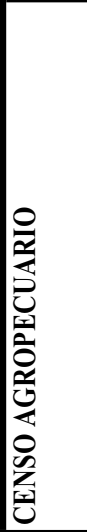 \\
\hline
\end{tabular}




\section{1. La cobertura geográfica}

Una primera razón se refiere a la cobertura geográfica de las encuestas disponibles. Desde este punto de vista, el censo agrícola y las encuestas del Instituto CUÁNTO no plantean problemas particulares. El censo agrícola es, desde luego, la fuente más exhaustiva de datos, ya que se dirige, por definición, al conjunto de los agricultores peruanos. Igualmente, las encuestas del Instituto CUÁNTO cubren tanto las zonas urbanas como las zonas rurales.

En cambio, la cobertura geográfica de las diferentes encuestas del INEI es variable. Las encuestas especializadas sobre el nivel de empleo, realizadas durante el tercer trimestre de cada año, y que son las más completas, no siempre han sido hechas sobre el conjunto del territorio nacional. La encuesta más reciente, hecha en el 2001, no cubrió sino las zonas urbanas del país. Del mismo modo, las encuestas sobre empleo permanentes, mensuales, y que serían las más útiles para apreciar la estacionalidad de la actividad agrícola, no cubren sino la zona de Lima.

Aunque los agricultores viven también en las zonas clasificadas como urbanas (es decir, los centros urbanos cuya población es superior a 2000 habitantes), la ausencia de muestreo de las zonas rurales ocasiona inevitablemente sesgos en la evaluación de la importancia y la naturaleza de las actividades complementarias de las explotaciones agrícolas. La proximidad de un centro urbano puede influir no solamente sobre el acceso de las poblaciones a empleos secundarios, sino también sobre el tipo de empleo ocupado. Se debe entonces renunciar, por las necesidades del análisis, a utilizar encuestas que contienen informaciones preciosas, ya que no permiten percibir correctamente la pluriactividad de las explotaciones agrícolas peruanas.

\section{2. La población encuestada}

Un segundo vacío de las estadísticas nacionales consiste en la definición de la población encuestada que, tratándose del mundo rural, no siempre es pertinente y a veces es incluso inapropiada para el objeto de nuestro análisis. Los datos del censo agrícola proporcionan informaciones sobre las actividades complementarias solamente en lo que se refiere al jefe de la explotación, es decir, a un individuo de sexo masculino cuya edad es por lo menos de 15 años. Los datos sobre las actividades productivas de los otros miembros del hogar no se refieren sino a su participación en los trabajos agrícolas. Esta restricción impide entonces el análisis que se puede hacer de las actividades complementarias desarrolladas por el conjunto de miembros de la explotación.

Las encuestas del INEI definen la población encuestada de manera restrictiva, siguiendo en esto las recomendaciones de la OIT, que define como niño a todo individuo de menos de 14 años y fija así la edad legal a partir de la cual un individuo tiene derecho a trabajar. Por consiguiente, y seguramente para evitar censar un número demasiado alto de niños que trabajan en relación con las normas internacionales, las encuestas realizadas por el INEI no censan la actividad de los miembros de la familia cuya edad es inferior a 14 años (a excepción de la última encuesta especializada sobre el nivel de empleo, que censa la actividad de los miembros de la familia a partir de los 6 años, pero que no cubre sino las zonas urbanas). 
Sólo las encuestas del Instituto CUÁNTO utilizan una definición de la población encuestada apropiada para el mundo agrícola. Se censan las actividades productivas de todos los miembros de los hogares cuya edad es igual o superior a 6 años y que corresponde (empíricamente) a la edad a partir de la cual los niños comienzan a participar en las actividades productivas. A partir de la encuesta de 1994 se ha calculado la tasa de participación de los niños, definida como la relación entre la población activa y la población total del grupo de edad, así como la distribución de sus ocupaciones principales y secundarias durante los doce meses anteriores a la encuesta.

Los resultados, que aparecen en los cuadros 2 y 3 , muestran una tasa significativa de actividad de los niños (grupo de 6-13 años): 20,8\% para el conjunto de la muestra. Se observarán las diferencias notables entre la tasa de actividad de los niños que residen en las zonas rurales $(23,9 \%)$ y la de los niños que residen en las zonas urbanas $(8,8 \%)$ que indica que la contribución de los niños a las actividades productivas es mucho más elevada en el medio rural que en el medio urbano.

Cuadro 2 - Tasa de actividad de los niños (6-13 años).

\begin{tabular}{lccc}
\hline & $\begin{array}{c}\text { Muestra } \\
\text { total }\end{array}$ & $\begin{array}{c}\text { Muestra } \\
\text { urbana }\end{array}$ & $\begin{array}{c}\text { Muestra } \\
\text { rural }\end{array}$ \\
\hline Tasa de participación & 20.8 & 8.8 & 23.9 \\
\hline
\end{tabular}

Fuente: CUÁNTO, 1994.

La distribución de las ocupaciones principales y secundarias de los niños muestra que su contribución a las actividades productivas está muy concentrada en los trabajos agrícolas dentro de la explotación (2). En las zonas rurales, la ocupación principal y secundaria declarada corresponde, en más del $90 \%$ de los casos, a un trabajo en el marco de la explotación familiar. Esta proporción es menor en las zonas urbanas, pero sigue teniendo un nivel elevado: $62,2 \%$ para la ocupación principal.

\section{Cuadro 3 - Distribución de las ocupaciones principales y secundarias de los niños} (6-13 años).

\begin{tabular}{|c|c|c|c|c|c|c|}
\hline & $\begin{array}{c}\text { Muestra } \\
\text { total }\end{array}$ & $\begin{array}{c}\text { Muestra } \\
\text { urbana }\end{array}$ & $\begin{array}{c}\text { Muestra } \\
\text { rural }\end{array}$ & $\begin{array}{c}\text { Muestra } \\
\text { total }\end{array}$ & $\begin{array}{c}\text { Muestra } \\
\text { urbana }\end{array}$ & $\begin{array}{c}\text { Muestra } \\
\text { rural }\end{array}$ \\
\hline & \multicolumn{3}{|c|}{ Ocupación principal } & \multicolumn{3}{|c|}{ Ocupación secundaria } \\
\hline Profesionales, científicos e intelectuales & 0,7 & & 0,8 & & & \\
\hline Técnicos & & & & 0,9 & & 0,9 \\
\hline Empleados de oficina & 5,6 & 34,5 & 2,7 & 6,9 & 33,3 & 6,2 \\
\hline Agricultores, ganaderos, pesqueros & 90,4 & 62,2 & 93,1 & 78,9 & & 80,8 \\
\hline Obreros & 0,6 & 1,1 & 0,6 & 1,6 & & 1,7 \\
\hline Obreros agrícolas & 2,7 & 2,2 & 2,8 & 11,8 & 66,7 & 10,4 \\
\hline Total & 100,0 & 100,0 & 100,0 & 100,0 & 100,0 & 100,0 \\
\hline
\end{tabular}

Fuente: CUÁNTO, 1994.

(2) Se ha modificado la nomenclatura inicial de las ocupaciones a fin de, por un lado, homogeneizarla con la nomenclatura de las ocupaciones de las encuestas del INEI, y por otro lado, de 
Estos son algunos de los datos que confirman que la omisión de la actividad de los niños en la casi totalidad de las encuestas del INEI plantea problemas. Por una parte, lleva a subestimar las necesidades de mano de obra de la agricultura, en particular durante los tiempos fuertes de los trabajos agrícolas en las zonas rurales. Efectivamente, es posible que el aporte de los niños a la puesta en valor de la explotación familiar no sea continuo. Aunque los datos disponibles no permiten el análisis de la estacionalidad de la actividad agrícola, se sabe que implica una gran variación en la movilización de la mano de obra familiar durante el ciclo agrícola. Durante la temporada alta de los trabajos agrícolas es cuando la ayuda de los niños puede ser esencial. Si es ese el caso, se confirma la hipótesis según la cual la mano de obra agrícola puede ser temporalmente escasa, ya que las necesidades de mano de obra de la explotación agrícola requieren la participación infantil en ciertos períodos del año. Por lo demás, esta estacionalidad probable de la actividad productiva infantil atenúa el conflicto potencial de la dedicación de su tiempo entre la escolaridad y las actividades productivas, ya que entonces está circunscrito a períodos particulares del año.

Por otra parte, la omisión de las actividades productivas de los niños lleva, aunque en menor medida, a subestimar también su contribución a la diversificación de las fuentes de ingresos. En las zonas urbanas en particular, la contribución productiva infantil a las actividades no agrícolas está lejos de ser despreciable: más o menos una tercera parte de ellos se declaran "empleados" como ocupación principal o secundaria.

\section{3. El período de referencia y el calendario agrícola}

Una tercera dificultad común a muchas de las encuestas está dada por el período de referencia que se aplica a las preguntas hechas. La mayor parte de las encuestas del INEI hacen referencia únicamente al empleo ocupado durante la semana anterior a la encuesta. Este referencial de tiempo muy corto plantea un problema esencial, el de la dependencia de las respuestas del período en el cual se ha realizado la encuesta.

En primer lugar, la actividad agrícola es una actividad estacional, en la que las necesidades de mano de obra (familiar u otra) son irregulares. Por consiguiente, el tamaño de la población activa y por lo tanto la tasa de actividad de los miembros de las explotaciones corre el riesgo de variar según el período en el que se ha realizado la encuesta.

En segundo lugar, sabiendo que los agricultores tienen tendencia a buscar empleos alternativos durante la temporada muerta de trabajos agrícolas, la probabilidad de que los individuos ejerzan una o más actividades complementarias en el momento de la encuesta está indudablemente en función del período en el que la encuesta se realiza.

\footnotetext{
adaptarla al objeto de nuestro estudio. En efecto, era necesario aislar una categoría que corresponde a las ocupaciones que forman parte de la explotación agrícola familiar de las otras ocupaciones agrícolas. Por lo tanto se ha diferenciado, dentro de la ocupación "obrero agrícola" a los individuos clasificados como ayudantes familiares de los individuos asalariados agrícolas. Bajo el término "agricultor" se ha agrupado al conjunto de individuos inscritos como agricultores en la nomenclatura inicial y que corresponde a menudo a los jefes de explotación y al conjunto de los obreros agrícolas cuyo estatus es el de ayudante familiar no remunerado.
} 
En tercer lugar, la referencia a la semana anterior a la encuesta presenta el inconveniente de no registrar más que las actividades complementarias eventuales que se realizan al mismo tiempo que la actividad en la explotación agrícola durante la semana anterior a la encuesta. Quedan automáticamente excluidas del registro las actividades que podrían ser realizadas en alternancia con la actividad agrícola a todo lo largo de un ciclo anual, que es un caso frecuente (3).

En cuarto lugar, la realización de las encuestas se extiende muy a menudo a lo largo de dos, tres e incluso cuatro meses, y la elección del período de realización no toma en cuenta de manera manifiesta el calendario agrícola. Así, las encuestas especializadas sobre el nivel de empleo se extienden a lo largo de un período que cubre en parte la temporada baja de trabajos agrícolas y en parte la temporada alta de los mismos. Como la semana de referencia no es idéntica para todas las explotaciones, los resultados sacados de estas encuestas son obligatoriamente ambiguos. La estacionalidad de la actividad agrícola, en particular, tiene tendencia a desaparecer.

En quinto lugar, las encuestas especializadas sobre el nivel de empleo del INEI incluyen un módulo adicional relativo a la actividad habitual para cada uno de los 12 meses anteriores. Permiten entonces determinar de manera más fiable las variaciones eventuales de la población activa agrícola, ya que es razonable suponer que los miembros de las explotaciones agrícolas declaran a la agricultura como actividad habitual todos los meses que corresponden a los trabajos agrícolas. Sin embargo, la ausencia de preguntas sobre otras actividades que podrían ejercer los miembros del hogar no permite dar cuenta de la importancia y de la diversidad de estas actividades durante el ciclo agrícola.

En resumen, los resultados procedentes de las diferentes encuestas disponibles conducen, como veremos posteriormente, a estimaciones variables no solamente de la población activa agrícola sino también de la importancia de las actividades complementarias de los activos de los hogares agrícolas según el período del año en el que la encuesta se realiza.

\section{4. Las nociones de actividad principal y secundaria}

Un cuarto y último problema que plantean las encuestas del INEI y del Instituto CUÁNTO ya mencionadas reside en el uso de las nociones de actividad principal y secundaria. En esas encuestas, la actividad principal está definida como la actividad que acapara más tiempo, y la actividad secundaria está definida como la actividad que acapara más tiempo después de la actividad principal. Aplicada al mundo rural, esta tipología no deja de ser ambigua.

La primera constatación que se puede hacer, producto de la experiencia personal de trabajo de campo de la autora, es que frecuentemente estas nociones son mal comprendidas por las personas entrevistadas, que tienen tendencia a enumerar el conjunto de actividades ejercidas durante un año considerándolas todas como

(3) Se sabe que una de las funciones fundamentales de las actividades complementarias es asegurar una continuidad en la generación de ingresos durante la temporada muerta de trabajos agrícolas. 
"principales", es decir, importantes de hecho según su punto de vista. La jerarquía de las diferentes actividades, en términos de tiempo, no tiene sentido para ellos. Esta "incomprensión" es potencialmente causa de numerosos errores en el registro de las respuestas que depende, en último caso, de la interpretación que hace el encuestador de las informaciones dadas por el encuestado.

La segunda observación importante es que las explotaciones agrícolas peruanas están generalmente empeñadas en estrategias de diversificación de la actividad agrícola, tal como lo han mostrado numerosos estudios (Cotlear, 1989; Gonzáles de Olarte, 1994; Gölte, 1980). Por consiguiente, en muchos casos, la segunda actividad, tal como aparece registrada en estas encuestas, es una actividad que forma parte de la explotación agrícola o agropastoral. En particular, todas las actividades que se refieren a los cuidados que se da a los animales tienen tendencia a ser registradas como actividades secundarias de la actividad de cultivo. En todos estos casos, las actividades complementarias de los activos agrícolas no son registradas.

Como ejemplo, se ha calculado en dos de las encuestas disponibles el número de dobles respuestas, es decir, el número de veces en que la ocupación secundaria declarada es idéntica a la ocupación principal. Los resultados que aparecen en el cuadro 4 muestran que el doble conteo es particularmente importante en las encuestas del Instituto CUÁNTO. Tratándose de la categoría “agricultores”, la principal causa de confusión viene de que las actividades de cría de animales han sido consideradas como ocupaciones diferentes a las actividades de cultivo, y por lo tanto registradas como actividades secundarias cada vez que la agricultura (en sentido estricto) era la actividad principal. En las encuestas del INEI el hecho de considerar la explotación agropastoral como un todo ha reducido considerablemente el porcentaje de errores de registro. Tratándose de la categoría "obreros agrícolas", se han diferenciado varias categorías que no presentan gran interés analítico(obreros de explotaciones agrícolas polivalentes, obreros de cultivos extensivos, obreros de cultivos arborícolas, obreros de crianza de ganado, etc.) y que han tenido como consecuencia registrar una misma ocupación con un nombre diferente.

\section{Cuadro 4 - Porcentaje de ocupaciones secundarias idénticas a la actividad principal.}

INEI $2000 \quad$ CUÁNTO 1994

\begin{tabular}{lcc} 
Fuerzas armadas y policiales & 0.0 & 0.0 \\
Miembros del poder ejecutivo & 0.0 & 0.0 \\
Profesionales, científicos e intelectuales & $\mathrm{ns}$ & 12.0 \\
Técnicos & 0.0 & 26.7 \\
Empleados de oficina & 0.0 & 11.1 \\
Vendedores y comerciantes & 4.6 & 6.7 \\
Agricultores, ganaderos, pesqueros & $\mathbf{3 . 5}$ & $\mathbf{4 0 . 7}$ \\
Obreros & 0.8 & 3.3 \\
Obreros agrícolas & $\mathbf{2 4 . 1}$ & $\mathbf{4 7 . 2}$ \\
\hline
\end{tabular}

Fuente: INEI, 2000; CUÁNTO, 1994. 
La ambigüedad operativa de las nociones de actividad principal y secundaria tiene dos consecuencias molestas: ocasiona en primer lugar dificultades de interpretación de los datos relacionada con la heterogeneidad del contenido de la categoría actividad secundaria, que corresponde unas veces a la actividad propia de la explotación agropastoral y otras veces a actividades complementarias como las que hemos definido. Después es muy probable que esa indefinición conceptual ocasione una sobrerrepresentación del sector agrícola en las actividades secundarias y que contrasta con los resultados del censo que no hace uso de estas categorías ( $c f$. infra).

Finalmente, en los cuestionarios del INEI no se prevé sino una sola actividad secundaria. Por lo tanto, todas las demás actividades que pueden llegar en tercera posición o más en la jerarquía del tiempo de trabajo no son tomadas en cuenta. En las encuestas del Instituto CUÁNTO, se prevé una ocupación adicional, pero sin que se registre ni el tipo de ocupación ni la rama de actividad. El análisis de esta variable muestra que alrededor del $5 \%$ de los individuos que declaran una ocupación secundaria durante los 7 últimos días declaran tener una ocupación adicional, y cerca del 12\% de los individuos que declaran una ocupación secundaria durante los 12 últimos meses declaran tener una ocupación adicional.

\section{UNA TENTATIVA DE ANÁLISIS DE LA IMPORTANCIA Y LAS CARACTERÍSTICAS DE LAS ACTIVIDADES COMPLEMENTARIAS DE LOS HOGARES AGRÍCOLAS}

A pesar de las numerosas imperfecciones de las estadísticas nacionales, se ha tratado de agrupar en esta sección el conjunto de elementos pertinentes que se podían escoger de las diferentes fuentes disponibles a fin de dar una idea, ciertamente aproximada, de la importancia y de las características de las actividades complementarias de las explotaciones agrícolas.

Para facilitar la exposición, pero también porque los datos provenientes de las diferentes fuentes no son directamente comparables entre sí, se presentarán los resultados que más resaltan para cada una de las fuentes tomadas separadamente.

\section{1. El censo agrícola}

El censo agrícola utiliza categorías que hacen difíciles las comparaciones con las otras fuentes. La categoría "profesión u oficio" de los agricultores censados no permite saber si esta profesión se ha ejercido durante los 12 meses previos al censo, ya sea como actividad principal o secundaria. En cambio, el censo agrícola diferencia explícitamente las actividades complementarias de la actividad relativa a la explotación agrícola propiamente dicha. Distingue también claramente las actividades complementarias realizadas en el lugar mismo de la explotación o fuera. Desgraciadamente, la información que es registrada sólo se refiere al jefe de la explotación, que es, según la definición del censo, un individuo de por lo menos 15 años.

La distribución de las actividades complementarias de los jefes de explotaciones agrícolas que figuran en el cuadro 5 hace aparecer varios elementos interesantes. El 
primero es la importancia no desdeñable de estas actividades, ya que el 16,4\% de los jefes de explotaciones agrícolas realizan actividades de diversificación en la explotación, y $25,7 \%$ realizan actividades fuera de la explotación. Entre las actividades desarrolladas en la explotación, las más importantes son la artesanía, que representa el 30\% del total, el comercio con $15,6 \%$ y la elaboración de productos derivados con 12,9\%. La estructura de la repartición de las actividades fuera de la explotación difiere considerablemente. Se notará la predominancia de la agricultura, fenómeno que vamos a volver a encontrar en la mayoría de las encuestas, ya que representa el 46,1\% de las actividades fuera de la explotación de los jefes, seguida de los sectores del comercio y de la construcción, que representan respectivamente el $15,1 \%$ y el $10 \%$.

\section{Cuadro 5 - Distribución de las actividades complementarias de los jefes de explotación.}

\begin{tabular}{|c|c|c|c|c|c|c|}
\hline \multicolumn{2}{|c|}{ Actividades en la explotación } & \multicolumn{5}{|c|}{ Actividades fuera de la explotación } \\
\hline & Total & & Costa & Sierra & Selva & Total \\
\hline Artesanías & 30.1 & Agricultura, ganadería, pesca & 49.8 & 37.6 & 51.3 & 46.1 \\
\hline Comercio & 15.6 & Explotación de minas y canteras & & & & 4.1 \\
\hline Elab. de productos derivados & 12.9 & Industrias manufactureras & & & & 1.1 \\
\hline Mecán. Herram. Transporte & 5.5 & Construcción & 5.7 & 13.0 & 3.9 & 10.0 \\
\hline Alquiler de máquinas agrícolas & 0.7 & Comercio & 14.1 & 15.7 & 9.0 & 15.1 \\
\hline \multirow[t]{4}{*}{ Zapatero, carpintero, albañil } & 0.2 & Hoteles y restaurantes & & & & 0.5 \\
\hline & & Transporte y comunicaciones & 4.9 & 3.2 & 2.4 & 3.7 \\
\hline & & Enseñanza privada & 2.7 & 2.8 & 2.3 & 2.7 \\
\hline & & Actividades de servicios & 3.1 & 3.6 & 2.2 & 3.1 \\
\hline Otro & 31.4 & Otro & 14.0 & 17.9 & 23.6 & 7.5 \\
\hline No especificado & 3.7 & No especificado & 5.7 & 6.3 & 5.3 & 6.2 \\
\hline Total & 100.0 & Total & 100.0 & 100.0 & 100.0 & 100.0 \\
\hline $\begin{array}{l}\text { En \% del número total } \\
\text { de productores }\end{array}$ & 16.4 & $\begin{array}{l}\text { En \% del número total } \\
\text { de productores }\end{array}$ & 28.5 & 24.9 & 26.7 & 25.7 \\
\hline
\end{tabular}

Fuente: Censo Agrícola, 1994.

Los resultados que figuran en el cuadro 5 hacen aparecer también una homogeneidad bastante marcada en la importancia de las actividades complementarias fuera de la explotación según las regiones naturales. Se observará sin embargo el porcentaje ligeramente más alto de productores de la Costa que realizan actividades productivas fuera de la explotación. Este resultado sorprende relativamente poco si se tiene en cuenta la menor estacionalidad de la agricultura costera, que permite absorber la mano de obra "excedentaria" en un período más largo, la existencia de grandes centros urbanos que ofrecen un mayor número de empleos, una red de comunicaciones en buen estado que facilitala inserción de los individuos en el mercado de trabajo, y, eventualmente, un mejor nivel de educación de los individuos.

De la misma forma, la estructura de las actividades complementarias varía poco entre las tres grandes regiones. El trabajo agrícola para otras explotaciones domina ampliamente las actividades complementarias en todas las regiones. Sin embargo, es en 
la Costa donde los productores agrícolas realizan más actividades complementarias agrícolas, estando marcado el caso de la Selva por la importancia de la pesca (que representa el 18,9\% del total agrícola). Este resultado confirma la capacidad de la agricultura costera para absorber la mano de obra disponible a causa, por un lado, de la existencia de infraestructuras de irrigación que permiten, si es el caso, varias cosechas anuales, y por otro lado a la gran concentración de cultivos intensivos en mano de obra (arroz, trigo, caña de azúcar). Por el contrario, los agricultores de la Sierra realizan menos actividades complementarias agrícolas por razones análogas, pero inversas a las de los agricultores de la Costa, como una estacionalidad más marcada de la actividad agrícola relacionada con la dependencia de los cultivos del régimen pluviométrico, y cultivos menos intensivos en mano de obra. El comercio y la construcción son los otros dos sectores privilegiados para las actividades complementarias.

Finalmente, el censo da informaciones valiosísimas sobre la estacionalidad de las actividades complementarias fuera de la explotación. En efecto, para cada mes del año se registra el número de los jefes de explotación que se han ausentado, así como el número de semanas de ausencia de la explotación agrícola. El gráfico 1 ilustra bien la estacionalidad de la actividad agrícola, marcada por una mayor ausencia entre los meses de julio a septiembre, meses que corresponden a la temporada muerta de los trabajos agrícolas relacionada con la ausencia de pluviometría en la mayoría de las zonas agrícolas del Perú. En cambio, los meses de noviembre y diciembre, y después abril y mayo, que corresponden a las siembras y a la cosecha, están marcados por una mayor presencia de los jefes de explotación.

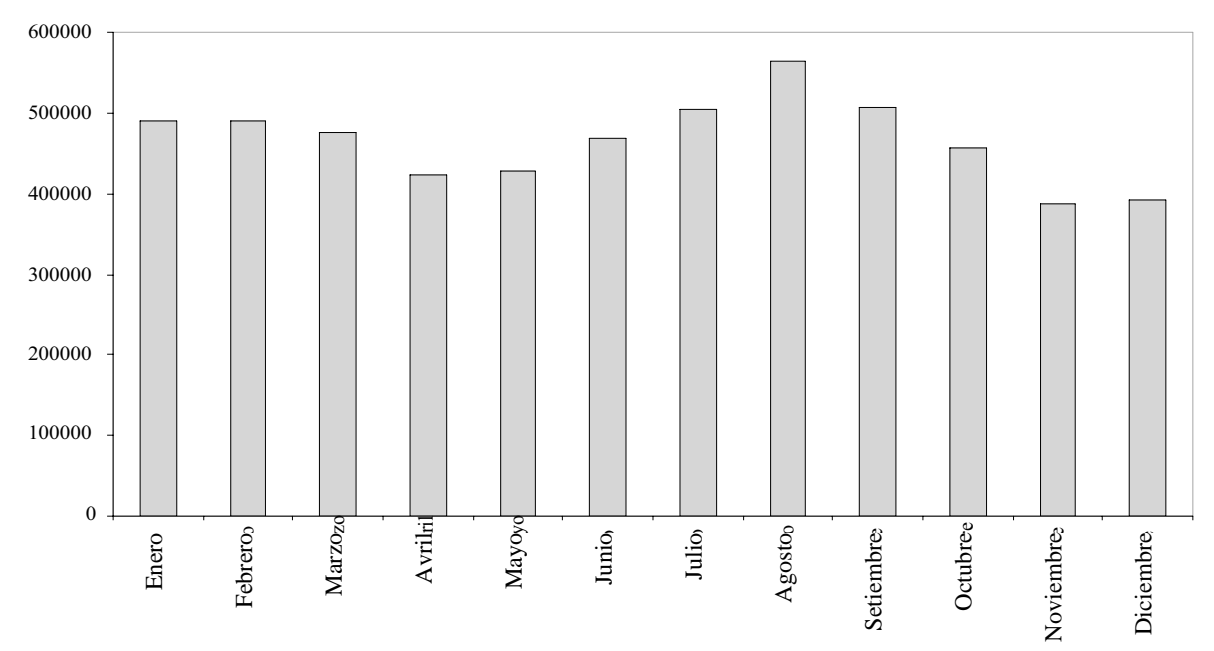

Gráfico 1 - Número de semanas de ausencia de los jefes de explotación durante el año. 


\section{2. La encuesta sobre el nivel de vida de los hogares del Instituto CUÁNTO.}

La encuesta sobre el nivel de vida de los hogares del Instituto CUÁNTO realizada en 1994, muy cerca del tiempo del censo agrícola, permite no solamente comparar en forma directa las dos fuentes, sino apreciar en qué medida coinciden algunos resultados (4). Se ha tratado de reconstruir, a partir de la base de datos de la encuesta sobre el nivel de vida de los hogares, una representación de las actividades complementarias de los miembros de las explotaciones agrícolas.

El criterio utilizado aquí no es tanto de saber si las diferentes ocupaciones posibles son ejercidas como actividad principal o secundaria, sino si esas ocupaciones son diferentes del trabajo dedicado a la explotación agrícola. Se han agrupado entonces en una misma categoría todas las ocupaciones que corresponden a un trabajo en la explotación agrícola, es decir, la ocupación “explotador agrícola” por un lado y “obrero agrícola” por el otro cuando esta última ocupación está asociada con el estatus de ayudante familiar no remunerado. Todas las demás ocupaciones, ya sean ejercidas como actividad principal o secundaria, han sido consideradas como actividad complementaria (5).

El cuadro 6 resume la participación de los miembros del hogar en actividades complementarias. Para el conjunto del Perú, esta participación es significativa y su dimensión es cercana a la dada por el censo: el 22,5\% de los activos ejerce una actividad complementaria, el 6,7\% ejercen dos actividades complementarias. La participación de los hombres es ampliamente superior $(33 \%)$ a la de las mujeres $(15,1 \%)$ y la de los niños aparece como relativamente marginal $(4,1 \%)$. Estas diferencias pueden explicarse no solamente por disparidades eventuales de las remuneraciones percibidas durante las actividades complementarias, sino también por la capacidad de los diferentes miembros del hogar para realizar estas actividades. La escolaridad en el caso de los niños y la carga de las tareas domésticas en el caso de las mujeres contribuyen a frenar su participación en las actividades complementarias, sobre todo si estas deben ser ejercidas fuera del hogar.

La participación de los miembros del hogar en las actividades complementarias varía poco según las regiones agroclimáticas. Se observará una participación ligeramente más alta en la Costa en relación con las otras regiones, debida principalmente a un número mayor de activos que ejercen dos actividades complementarias, las mujeres en particular. Esta mayor participación puede ser una consecuencia de ingresos agrícolas más altos por cabeza. En efecto, desde un punto de vista microeconómico, mejores

(4) Este trabajo necesitó algunas modificaciones de la base de datos de la encuesta CUÁNTO. En efecto, no todos los hogares de las muestras en la encuesta CUÁNTO son explotaciones agrícolas. Por lo tanto, hubo que extraer de la base de datos el subconjunto de hogares que son explotaciones agrícolas. La selección se hizo a partir del módulo "Ingreso del productor agrícola" de la encuesta. Se consideraron los hogares que habían declarado un ingreso agrícola como productor independiente.

(5) Se recordará que los datos que se obtienen subestiman la importancia de las actividades complementarias en la medida en que estas actividades no han sido registradas en la base de datos inicial para todos los activos cuya ocupación principal y secundaria es "explotador agrícola" u "obrero agrícola". Falta también el registro de las actividades de los activos que ejercen más de dos actividades complementarias. 
Cuadro 6 - Porcentaje de activos que ejercen una actividad complementaria.

\begin{tabular}{lcccc}
\hline & Hombres & Mujeres & Niños & Todos \\
\cline { 2 - 5 } Costa & & & & \\
\cline { 2 - 5 } Una ocupación complementaria & 28.4 & 16.5 & 4.6 & 23.0 \\
$\begin{array}{l}\text { Dos ocupaciones complementarias } \\
\text { Sierra }\end{array}$ & 9.0 & 14.5 & 0.0 & 10.4 \\
Una ocupación complementaria & 36.2 & 14.3 & 4.2 & 22.9 \\
Dos ocupaciones complementarias & 8.1 & 4.9 & 0.3 & 5.7 \\
Selva & & & & \\
Una ocupación complementaria & 30.1 & 15.4 & 3.8 & 20.3 \\
Dos ocupaciones complementarias & 7.8 & 4.9 & 1.3 & 5.6 \\
Perú & & & & \\
Una ocupación complementaria & 33.0 & 15.1 & 4.1 & 22.5 \\
Dos ocupaciones complementarias & 8.3 & 7.0 & 0.5 & 6.7 \\
\hline
\end{tabular}

Fuente: CUÁNTO, ENNIV, 1994.

ingresos agrícolas significan posibilidades de inversión del excedente agrícola en actividades complementarias. A nivel regional o nacional, la mejoría de los ingresos agrícolas aumenta la demanda final de productos de consumo y de servicios, de insumos o incluso de servicios de transformación y de comercialización de los productos agrícolas. Esta mejoría estimula entonces la creación local de empresas, que van a dar lugar a su vez al aumento y a la diversidad de los empleos localmente disponibles.

En los cuadros 7 y 8 se presenta la distribución de las ramas de actividad de las ocupaciones complementarias de los activos de las explotaciones agrícolas, así como el estatus durante el ejercicio de estas actividades. Las actividades complementarias de los activos agrícolas se distribuyen entre tres grandes ramas de actividad, que son, por orden de importancia: la agricultura (39\%) (6), el comercio (19,5\%), el sector de las industrias manufactureras $(11,5 \%)$ y finalmente la construcción $(7,2 \%)$. Sin embargo, esta repartición difiere un poco según las categorías de población a que se refiere. Los hombres, en promedio, están más a menudo empleados en la agricultura $(45,4 \%)$ que las mujeres $(22,6 \%)$, concentrándose principalmente estas últimas en el sector del comercio $(31,5 \%)$, de las industrias manufactureras $(16,0 \%)$ y de los servicios $(15,1 \%)$. Después de la agricultura, los sectores predilectos de los hombres son el comercio $(14,4 \%)$, la construcción $(9,9 \%)$ y las industrias manufactureras $(9,8 \%)$. Los niños están empleados principalmente en la agricultura $(59,5 \%)$, el comercio $(22,1 \%)$ y los servicios $(8,9 \%)$.

(6) Los resultados que se obtienen son considerablemente diferentes a los obtenidos a partir de esta misma encuesta cuando las categorías de análisis utilizadas son las de la ocupación principal y secundaria (Valdivia \& Robles, 1997). Se obtiene en particular una predominancia mucho menos marcada de la agricultura en las actividades complementarias comparada con su importancia en las actividades secundarias. 


\section{Cuadro 7 - Distribución de los sectores de actividad de las ocupaciones complementarias.}

\begin{tabular}{|c|c|c|c|c|c|c|c|c|c|c|c|c|c|c|c|c|}
\hline \multirow[b]{3}{*}{ Agric., ganad., caza, pesca } & \multicolumn{4}{|c|}{ Costa } & \multicolumn{4}{|c|}{ Sierra } & \multicolumn{4}{|c|}{ Selva } & \multicolumn{4}{|c|}{ Perú } \\
\hline & Homb. & Mujer & Niño & Total & Homb. & Mujer & Niño & Total & Homb. & Mujer & Niño & Total & Homb. & Mujer & Niño & Total \\
\hline & 51.9 & 27.0 & 75.0 & 43.2 & 41.1 & 20.2 & 66.7 & 36.1 & 50.5 & 20.5 & 40.1 & 41.7 & 45.4 & 22.6 & 59.5 & 39.0 \\
\hline Explot. de minas y canteras & & & & & 1.0 & 0.5 & & 0.8 & & & & & 0.6 & 0.2 & 0.0 & 0.5 \\
\hline Industrias manufactureras & 2.8 & 9.6 & & 5.2 & 12.5 & 19.0 & 5.6 & 14.1 & 11.5 & 20.4 & & 13.6 & 9.8 & 16.0 & 3.4 & 11.5 \\
\hline Electricidad, gas y agua & & & & & 0.7 & 0.9 & & 0.8 & 0.3 & & & 0.2 & 0.5 & 0.5 & & 0.5 \\
\hline Construcción & 2.8 & & & 1.8 & 13.8 & 1.8 & & 10.3 & 7.7 & 0.8 & 6.7 & 5.7 & 9.9 & 1.1 & 2.0 & 7.2 \\
\hline Comercio & 20.0 & 32.8 & & 24.4 & 12.8 & 31.2 & 16.7 & 17.7 & 11.0 & 30.0 & 39.8 & 17.4 & 14.4 & 31.5 & 22.1 & 19.5 \\
\hline Hoteles y restaurantes & & 0.9 & & 0.3 & 0.8 & 2.3 & & 1.2 & 0.3 & 5.7 & & 1.9 & 0.5 & 2.4 & & 1.1 \\
\hline Transporte y comunicaciones & 13.3 & & 25.0 & 8.7 & 3.9 & & & 2.8 & 6.4 & & & 4.4 & 6.7 & 0.0 & 2.1 & 4.7 \\
\hline Intermediación financiera & & & & & 0.8 & 1.4 & & 1.0 & 1.0 & & & 0.7 & 0.7 & 0.7 & & 0.7 \\
\hline Actividades inmobiliarias & & & & & 1.3 & 1.9 & & 1.5 & 1.0 & 2.4 & 6.7 & 1.6 & 0.9 & 1.4 & 2.0 & 1.1 \\
\hline Adm. pública y defensa & 7.8 & & & 5.0 & 5.3 & 1.8 & & 4.3 & 2.7 & & & 1.8 & 5.5 & 0.9 & & 4.1 \\
\hline Enseñanza privada & 0.7 & 14.1 & & 5.4 & 3.2 & 5.3 & & 3.7 & 4.1 & 1.6 & & 3.2 & 2.7 & 7.7 & & 4.1 \\
\hline Actividades de servicios & 0.7 & 15.8 & & 6.0 & 2.7 & 13.5 & 11.1 & 5.8 & 3.3 & 18.7 & 6.7 & 7.8 & 2.3 & 15.1 & 8.9 & 6.2 \\
\hline Total & 100.0 & 100.0 & 100.0 & 100.0 & 100.0 & 100.0 & 100.0 & 100.0 & 100.0 & 100.0 & 100.0 & 100.0 & 100.0 & 100.0 & 100.0 & 100.0 \\
\hline
\end{tabular}

Fuente: CUÁNTO, ENNIV, 1994.

Cuadro 8 - Distribución de los estatus de las actividades complementarias.

\begin{tabular}{|c|c|c|c|c|c|c|c|c|c|c|c|c|c|c|c|c|}
\hline \multirow[b]{3}{*}{ Autoempleo } & \multicolumn{4}{|c|}{ Costa } & \multicolumn{3}{|c|}{ Sierra } & \multicolumn{5}{|c|}{ Selva } & \multicolumn{4}{|c|}{ Perú } \\
\hline & Homb & Mujer & Niño & Total & Homb. & Mujer & Niño & Total & Homb & Mujer & Niño & Total & Homb. & Mujer & Niño & Total \\
\hline & 37.3 & 23.4 & 25.0 & 32.3 & 37.4 & 54.8 & 11.8 & 41.4 & 33.1 & 55.7 & 7.2 & 38.8 & 36.7 & 44.2 & 14.7 & 38.4 \\
\hline Ayudante familiar & 0.2 & 20.8 & & 7.5 & 2.9 & 12.0 & 29.4 & 5.8 & 4.1 & 12.2 & 35.6 & 7.5 & 2.4 & 15.0 & 24.1 & 6.6 \\
\hline Asalariado & 62.5 & 55.8 & 75.0 & 60.2 & 59.7 & 33.3 & 64.7 & 52.8 & 62.7 & 32.1 & 42.8 & 53.8 & 61.0 & 40.8 & 61.2 & 55.1 \\
\hline Total & 100.0 & 100.0 & 100.0 & 100.0 & 100.0 & 100.0 & 100.0 & 100.0 & 100.0 & 100.0 & 100.0 & 100.0 & 100.0 & 100.0 & 100.0 & 100.0 \\
\hline
\end{tabular}

Fuente: CUÁNTO, ENNIV, 1994.

De acuerdo con los resultados del censo, la distribución de las ramas de actividades complementarias varía bastante poco según las regiones. Se vuelve a encontrar también una mayor concentración de las actividades complementarias de los activos en el sector agrícola en la Costa en relación con las otras regiones. Se observará además una mayor proporción de las actividades complementarias de los hombres en el comercio y el transporte, y de las actividades complementarias de las mujeres en la educación. Otro resultado común con los del censo es que en la Sierra la construcción es un sector relativamente más importante que en las otras regiones. Además, la participación de los hombres, de las mujeres y de los niños en las actividades manufactureras (7) es muy superior al promedio nacional, y la proporción de niños en las actividades de servicios es también más alta. En la Selva, las actividades complementarias de las mujeres aparecen más diversificadas que en otras partes. Son relativamente pocas en el sector agrícola, pero relativamente más frecuentes en las industrias manufactureras, la hotelería y los restaurantes y los servicios. En cuanto a los hombres, escogen principalmente la agricultura y las industrias manufactureras.

(7) Esta rama de actividad, cuya importancia puede sorprender, agrupa de hecho actividades tanto industriales como artesanales. Se puede suponer razonablemente, en el caso presente, que la artesanía representa la parte principal del conjunto de actividades de la rama. 
El estatus en el empleo ocupado da indicaciones interesantes sobre el dinamismo del mercado de trabajo. Una primera conclusión que se impone, a la vista de las cifras del cuadro 8, es la predominancia del estatus de trabajador asalariado $(55,1 \%)$ cuando los activos de las explotaciones agrícolas ejercen una actividad complementaria. La parte del autoempleo sigue sin embargo siendo importante ya que representa el $38,4 \%$ del conjunto de los estatus ocupados cuando se realizan actividades complementarias. El estatus de ayudante familiar no remunerado es por su parte marginal $(6,6 \%)$. Estos resultados sugieren un relativo desarrollo del mercado de trabajo y una dinámica mayor de lo que han dejado suponer los estudios anteriores (Valdivia \& Robles, 1997), que al no distinguir claramente en las actividades principales y secundarias lo que corresponde a la explotación de las demás actividades, subestiman la importancia del trabajo asalariado (el estatus de un activo asignado a los trabajos de explotación, como ocupación principal o secundaria, es por definición el autoempleo o como ayudante familiar no remunerado).

La actividad asalariada es sobre todo cosa de los hombres, mientras que las mujeres tienen una propensión mayor a ejercer actividades complementarias en las cuales son autoempleadas. Estas diferencias de estatus entre los individuos pueden ser el índice de una divergencia en la capacidad para participar en el mercado de trabajo. Las mujeres, de manera general, tienen una menor propensión a ocuparse en actividades asalariadas debido a las tareas domésticas y familiares que están en gran parte a su cargo. La artesanía, el comercio o cualquier otra forma de actividad que pueda ejercerse en el hogar se adapta particularmente a la división tradicional del trabajo según el género.

La distribución de los estatus de los trabajadores varía poco según las regiones. Se debe señalar sin embargo que la proporción de asalariados es relativamente más alta en la Costa, comparándola con las otras regiones, en particular entre las mujeres. En la medida en que la agricultura es allí la actividad complementaria principal, el desarrollo particular de la agricultura en esta región es probablemente la fuente de una gran demanda de trabajo asalariado. Se puede suponer, efectivamente, que la carencia de mano de obra de las grandes explotaciones comerciales costeras, combinada con la carencia de recursos de las explotaciones familiares, ha favorecido el desarrollo del trabajo asalariado agrícola. En cambio, en las condiciones de producción andinas, caracterizadas por la baja productividad de la agricultura y por el bajo precio de los productos agrícolas, pocos productos permiten remunerar las jornadas de trabajo exteriores. Por consiguiente, el trabajo asalariado no puede desarrollarse fácilmente.

Finalmente, no ha sido posible distinguir si estas actividades se realizan en la explotación o fuera de la explotación, ya que la información no ha sido registrada sistemáticamente, lo que hace difícil la comparación de los datos del censo. Sin embargo, se observará que las conclusiones que se pueden sacar del análisis independiente de estas fuentes son parecidas. Algunas características de las actividades complementarias se vuelven a encontrar, en particular la jerarquía de su repartición entre las ramas, la relativa estabilidad de esta repartición según las regiones, la proporción ligeramente más alta de actividades complementarias en el sector agrícola en la Costa. 


\section{3. Las encuestas del INEI}

La mayoría de las agriculturas del mundo se caracterizan por una gran estacionalidad, cuyos tiempos fuertes están marcados por el régimen de lluvias. Esta estacionalidad se refleja generalmente en la utilización de la mano de obra agrícola según los momentos del calendario agrícola y eventualmente en los cambios de sector de actividad durante el ciclo agrícola. Cuantificar estas variaciones supone disponer de encuestas sobre el empleo realizadas en varias épocas del año, que representen los diferentes momentos del calendario agrícola.

En el Perú, sólo las fuentes del INEI permitían hacer un trabajo así. Se han utilizado entonces tres encuestas del año 2000 (8), a fin de analizar por una parte las variaciones eventuales de la población activa en el curso del año y por otra las variaciones de la distribución de las ocupaciones principales y secundarias. Estas encuestas, desde luego, no son estrictamente comparables entre sí, debido a que tienen un muestreo diferente. Los resultados que figuran en los cuadros siguientes tienen como único objetivo verificar si estas encuestas registran a pesar de todo la estacionalidad de la actividad agrícola. Si esta estacionalidad está marcada, se deberían observar en el curso del año cambios notables no solamente en el número de activos sino también en la importancia relativa de las diferentes ramas de actividad.

El cuadro 9 presenta las variaciones del tamaño de la población activa en el curso del año 2002. La primera observación importante que se puede hacer a la vista de estas cifras es que la proporción de la población activa desocupada, tanto en desocupación abierta como oculta (9), aparece sumamente baja: entre $1,4 \%$ y $0,8 \%$ para la primera, y entre $2,3 \%$ y $3 \%$ para la segunda. Además, sólo la proporción de la población activa en situación de desocupación oculta difiere entre los hombres y las mujeres: mientras que es estable en alrededor del 1\% para los hombres, varía del 3,7\% al 5,4\% para las mujeres según el período del año.

Una segunda característica que se observa en el cuadro 9 es la débil variación del número de activos masculinos durante el año. En cambio, esta variación es perceptible para las mujeres que se retiran en forma evidente de la población activa durante el tercer trimestre del año: solamente el 68,3\% de las mismas son declaradas activas, mientras que esta proporción sube a 79,5\% en el cuarto trimestre. Esta situación no sorprende porque las entradas y salidas de la mano de obra femenina de la población activa sirven a menudo para ajustar la oferta de mano de obra a las necesidades muy estacionales de la actividad agrícola (10).

(8) Se trata de la encuesta "Educación, salud y aspectos demográficos" del segundo trimestre del 2000, de la "encuesta especializada sobre el empleo y los ingresos" del tercer trimestre, y de la encuesta "Condiciones de vida y pobreza" del cuarto trimestre. No existe ninguna encuesta realizada durante el primer trimestre.

(9) El INEI define como "desocupado oculto" a toda persona que no trabaja y que no está en busca de un trabajo debido a las dificultades que hay para encontrarlo. Por lo tanto, no se trata de "desocupados ocultos" en el sentido en que lo entendía Lewis, sino más bien de "desocupados desalentados".

(10) Se recuerda que las personas de menos de 14 años no han sido encuestadas. Se deberían constatar variaciones intraanuales aún más elevadas de la población activa en este grupo de edad. 
Cuadro 9 - El tamaño de la población activa durante el año 2000.

\begin{tabular}{lrrrrrrrrr}
\hline & \multicolumn{3}{c}{ Trimestre II } & \multicolumn{3}{c}{ Trimestre III } & \multicolumn{3}{c}{ Trimestre IV } \\
\cline { 2 - 10 } & Hombre & Mujer & Total & Hombre & Mujer & Total & Hombre & Mujer & Total \\
\cline { 2 - 10 } No PEA & 11,2 & 27,8 & 19,5 & 12,0 & 31,7 & 21,7 & 12,4 & 28,6 & 20,5 \\
No responde & 1,2 & 0,9 & 1,1 & 0,0 & 0,0 & 0,0 & 0,0 & 0,0 & 0,0 \\
PEA & 87,6 & 71,3 & 79,4 & 88,0 & 68,3 & 78,3 & 87,6 & 71,4 & 79,5 \\
& & & & & & & & & \\
Ocupado & 97,3 & 93,6 & 95,7 & 98,7 & 98,5 & 98,6 & 97,9 & 95,5 & 96,8 \\
Desocupado abierto & 1,7 & 1,0 & 1,4 & 1,3 & 1,5 & 1,4 & 0,8 & 0,8 & 0,8 \\
Desocupado oculto & 1,1 & 5,4 & 3,0 & nd & nd & nd & 1,2 & 3,7 & 2,3 \\
Total & 100,0 & 100,0 & 100,0 & 100,0 & 100,0 & 100,0 & 100,0 & 100,0 & 100,0 \\
\hline
\end{tabular}

Fuente: Trimestre II: Encuesta sobre educacion, salud, empleo e ingreso, INEI, 2000.

Trimestre III: Encuesta especializada de niveles de empleo, INEI, 2000.

Trimestre IV: Encuesta sobre las condiciones de vida y pobreza, INEI, 2000.

La repartición de las ramas de actividad en las que han estado empleados los miembros de los hogares agrícolas durante el año figura en el cuadro 10. Se observará la sorprendente estabilidad de la estructure de los sectores de actividad durante el año. El trabajo en la explotación propia ocupa como actividad principal entre el 70 y el $74 \%$ de los activos de las explotaciones agrícolas según los trimestres y el $61 \%$ aproximadamente como actividad secundaria a lo largo de todo el año. Esta estabilidad parece además confirmada por los datos de la encuesta especializada sobre el nivel de empleo que registra la actividad habitual para cada uno de los 12 meses anteriores a la encuesta. Los resultados que figuran en el cuadro 11 muestran que cada mes la actividad habitual declarada es la agricultura en alrededor del $80 \%$ de los casos, y que las variaciones alrededor de este promedio son sumamente bajas. El 20\% restante se reparte, por orden de importancia, entre los sectores de servicios, de comercio, de industrias manufactureras y de la construcción.

La baja estacionalidad de la actividad agrícola, tal como aparece a partir de los datos del INEI, requiere algunos comentarios. En un primer momento se puede suponer que la estacionalidad de la agricultura peruana es realmente poco marcada. Tres argumentos van en este sentido. En la Costa, la existencia de infraestructuras de irrigación, y por lo tanto la posibilidad de producir varias cosechas por año, contribuye a reducir la estacionalidad de la actividad agrícola. En la Sierra, la estacionalidad de las operaciones de cultivo puede ser compensada en parte por la estabilidad de las actividades pastorales. En efecto, la crianza de ganado, cuya importancia relativa en relación con los cultivos es evidentemente variable según las explotaciones, requiere una mano de obra permanente. Finalmente, es posible que exista una división marcada del trabajo entre los individuos asignados al trabajo en la explotación y los que están asignados a otras actividades. Si es así, entonces es lógico que los cambios de rama de actividad durante el ciclo agrícola sean poco numerosos.

Sin embargo, la ausencia de estacionalidad aparente de la actividad agrícola puede provenir también de las metodologías de encuesta. En primer lugar, se recordará 
que la semana de referencia varía de un grupo de explotaciones a otro dentro de la misma encuesta a causa del tiempo tomado para la realización de las encuestas. En total, se dispone entonces de datos que hacen referencia a un continuum de semanas que se extiende a lo largo de casi 10 meses. En estas condiciones, la estacionalidad de la actividad agrícola tiene pocas posibilidades de aparecer. Luego, la actividad habitual registrada durante cada mes tiene muchas posibilidades de ser la misma, en este caso la agricultura, ya que los cambios eventuales de ocupación y de rama de actividad son de una duración inferior a un mes. El censo agrícola, que registra las semanas de ausencia de los jefes de explotación, sugiere una estacionalidad marcada de la actividad agrícola.

\section{Cuadro 10 - Distribución de los sectores de actividad principal y secundaria del año 2000.}

\begin{tabular}{|c|c|c|c|c|c|c|c|c|c|c|c|c|c|c|c|c|c|}
\hline & \multicolumn{9}{|c|}{ Sector de actividad principal } & \multicolumn{8}{|c|}{ Sector de actividad secundaria } \\
\hline & \multicolumn{3}{|c|}{ Trimestre II } & \multicolumn{3}{|c|}{ Trimestre III } & \multicolumn{3}{|c|}{ Trimestre IV } & \multicolumn{3}{|c|}{ Trimestre II } & \multicolumn{3}{|c|}{ Trimestre III } & \multicolumn{2}{|c|}{ Trimestre IV } \\
\hline & Hom. & Mujer T & Total & Hom. 1 & Mujer T & Total H & Hom. 1 & Mujer & Total & Hom. & Mujer & Total & Hom. & Mujer & Total H & Hom. Mujer & Total \\
\hline Traba & 74.4 & 74.8 & 74.6 & 75.5 & 72.6 & 74.2 & 60.7 & 68.4 & 70.2 & 53.6 & 75.5 & 61.3 & 56.6 & 67.9 & 60.8 & $57.9 \quad 65.5$ & $\overline{60.7}$ \\
\hline Agricultt & 8.8 & 4.0 & 6.5 & 7.1 & 3.3 & 5.4 & 12.8 & 3.4 & 6.9 & 19.3 & 4.9 & 14.2 & 13.4 & 4.3 & 10.0 & $17.5 \quad 4.7$ & 12.8 \\
\hline Explot: & 1.0 & 0.0 & 0.6 & 0.3 & 0.0 & 0.2 & 0.3 & 0.0 & 0.1 & 0.2 & 0.0 & 0.1 & 0.6 & 0.0 & 0.4 & $0.0 \quad 0.0$ & \\
\hline Indus & 4.5 & 3.0 & 3.8 & 3.5 & 5.3 & 4.3 & 3.4 & 6.5 & 4.8 & 3.7 & 5.7 & 4.4 & 5.9 & 9.0 & 7.0 & 5.910 .1 & 7.5 \\
\hline Sumir & 0.0 & 0.0 & 0.0 & 0.0 & 0.0 & 0.0 & 0.0 & 0.0 & 0.0 & 0.0 & 0.0 & 0.0 & 0.0 & 0.0 & 0.0 & $0.4 \quad 0.0$ & \\
\hline & 1.8 & 0.1 & 1.0 & 3.0 & 0.1 & 1.7 & 3.3 & 0.0 & 1.8 & 2.6 & 0.0 & 1.7 & 3.8 & 0.0 & 2.4 & $2.5 \quad 0.0$ & 1.6 \\
\hline & 3.4 & 10.4 & 6.7 & 3.5 & 10.8 & 6.8 & 5.4 & 13.7 & 9.2 & 13.7 & 12.7 & 13.3 & 12.3 & 11.8 & 12.1 & $11.2 \quad 11.3$ & 11.3 \\
\hline Hotel & 0.3 & 2.3 & 1.2 & 0.4 & 2.8 & 1.5 & 0.4 & 3.4 & 1.8 & 0.0 & 0.4 & 0.1 & 0.6 & 12 & 1.9 & $0.3 \quad 3.0$ & 1.3 \\
\hline & 1.7 & 0.0 & 0.9 & 2.3 & 0.0 & 1.3 & 2.1 & 0.3 & 1.3 & 2.8 & 0.0 & 1.8 & 2.8 & 0.0 & 1.8 & $2.9 \quad 0.5$ & 2.0 \\
\hline & 0.0 & 0.1 & 0.1 & 0.0 & 0.0 & 0.0 & 0.0 & 0.0 & 0.0 & 0.0 & 0.0 & 0.0 & 0.0 & 0.0 & 0.0 & $0.0 \quad 0.0$ & \\
\hline . & 0.4 & 0.3 & 0.3 & 0.2 & 0.2 & 0.2 & 0.5 & 0.0 & 0.3 & 0.4 & 0.0 & 0.2 & 0.1 & 0.1 & 0.1 & $0.2 \quad 0.0$ & \\
\hline Admin & 1.4 & 0.7 & 1.1 & 1.2 & 0.6 & 0.9 & 1.2 & 0.2 & 0.7 & 1.9 & 0.0 & 1.2 & 0.9 & 0.0 & 0.6 & $\begin{array}{ll}0.0 & 1.2\end{array}$ & \\
\hline Enseña & 1.5 & 1.3 & 1.4 & 2.1 & 1.7 & 1.9 & 1.2 & 1.7 & 1.4 & 0.0 & 0.0 & 0.0 & 0.4 & 0.6 & 0.5 & $1.2 \quad 3.8$ & \\
\hline & 0.8 & 3.2 & 1.9 & 0.7 & 2.6 & 1.6 & 0.7 & 2.4 & 1.5 & 2.0 & 0.8 & 1.6 & 2.6 & 2.1 & 2.4 & $0.0 \quad 0.0$ & 2.1 \\
\hline Total & 00.0 & 100.01 & 100.0 & 100.01 & 100.01 & 100.01 & 100.01 & 100.01 & 100.0 & 100.0 & 100.0 & 100.0 & 100.01 & 100.0 & 100.01 & 100.0100 .0 & 100.0 \\
\hline
\end{tabular}

Fuente: Trimestre II: Encuesta sobre educación, salud, empleo e ingreso, INEI,2000.

Trimestre III: Encuesta especializada de niveles de empleo, INEI, 2000.

Trimestre IV: Encuesta sobre las condiciones de vida y pobreza, INEI, 2000.

\section{Cuadro 11 - Actividad habitual durante los últimos doce meses.}

\begin{tabular}{lrrrrrrrrrrrr}
\hline & \multicolumn{1}{c}{ août-99 Set-99 } & oct-99 & nov-99 & déc-99 & janv-00 & févr-00 & mars-00 & avr-00 & mai-00 juin-00 juil-00 \\
\cline { 2 - 14 } Agricultura, ganadería, pesca & 79,6 & 79,6 & 80,2 & 80,3 & 80,1 & 80,8 & 80,8 & 80,8 & 80,1 & 80,3 & 79,6 & 78,8 \\
Explotaciones mineras & 0,3 & 0,3 & 0,3 & 0,3 & 0,3 & 0,3 & 0,3 & 0,3 & 0,3 & 0,3 & 0,3 & 0,3 \\
Industrias manufactureras & 2,9 & 2,9 & 2,7 & 2,7 & 2,6 & 2,6 & 2,6 & 2,7 & 2,8 & 2,7 & 2,9 & 3,1 \\
Agua, gas y electricidad & 0,1 & 0,0 & 0,0 & 0,0 & 0,0 & 0,0 & 0,0 & 0,0 & 0,0 & 0,0 & 0,0 & 0,0 \\
Construcción & 1,3 & 1,2 & 1,1 & 1,0 & 1,1 & 1,0 & 1,1 & 1,0 & 1,0 & 0,9 & 1,0 & 1,1 \\
Comercio & 6,6 & 6,7 & 6,6 & 6,7 & 6,5 & 6,3 & 6,4 & 6,4 & 6,6 & 6,6 & 6,7 & 6,8 \\
Hoteles y restaurantes & 1,4 & 1,4 & 1,4 & 1,3 & 1,4 & 1,4 & 1,4 & 1,4 & 1,3 & 1,4 & 1,4 & 1,4 \\
Transporte y comunicaciones & 0,9 & 0,9 & 0,9 & 0,9 & 1,0 & 0,9 & 0,9 & 0,9 & 1,0 & 0,9 & 1,0 & 1,1 \\
Servicios & 7,0 & 7,0 & 6,8 & 6,7 & 7,0 & 6,5 & 6,5 & 6,5 & 6,8 & 7,0 & 7,1 & 7,4 \\
Total & 100,0 & 100,0 & 100,0 & 100,0 & 100,0 & 100,0 & 100,0 & 100,0 & 100,0 & 100,0 & 100,0 & 100,0 \\
\hline
\end{tabular}

Fuente: Encuesta especializada de niveles de empleo, INEI, 2000. 
Finalmente, nos hemos dedicado al mismo ejercicio que para la encuesta sobre el nivel de vida de los hogares del Instituto CUÁNTO, es decir, reconstruir a partir de las bases de datos una representación de las actividades complementarias de los miembros de las explotaciones agrícolas. Los resultados, presentados en los cuadros 12 y 13, llevan a tres observaciones.

\section{Cuadro 12 - Porcentaje de activos que ejercen una actividad complementaria.}

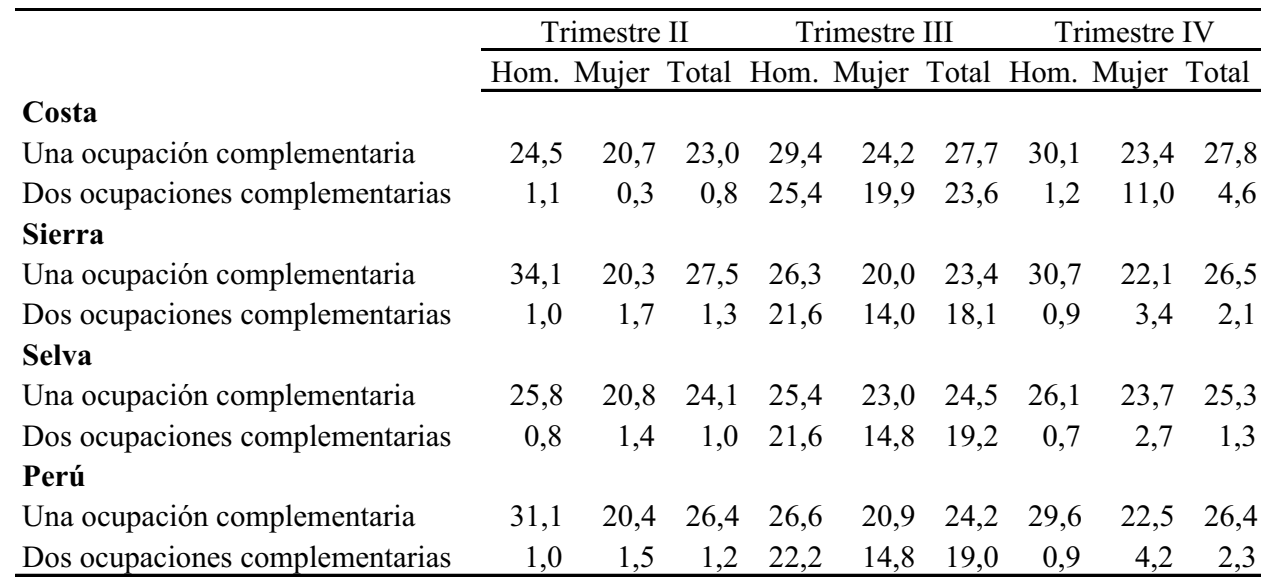

Fuente: Trimestre II: Encuesta sobre educacion, salud, empleo e ingreso, INEI, 2000.

Trimestre III: Encuesta especializada de niveles de empleo, INEI, 2000.

Trimestre IV: Encuesta sobre las condiciones de vida y pobreza, INEI, 2000.

La primera es que la participación de los miembros del hogar en actividades complementarias aparece considerablemente más alta que la que se desprende de los resultados de la encuesta CUÁNTO, cualquiera que sea el trimestre del año considerado. Este resultado se explica por una tasa de participación de las mujeres claramente más alta (20-22,5\%) que en la encuesta CUÁNTO (alrededor del 15\%), manteniéndose estable la tasa de participación de los hombres. La principal razón que explica estas diferencias es el mejor registro de las actividades complementarias en las encuestas del INEI por el hecho de que la interpretación de la noción de actividad secundaria es menos ambigua. En la encuesta de CUÁNTO las actividades secundarias de las mujeres consisten en gran parte en actividades de crianza de animales. Las encuestas del INEI, que consideran la explotación agropastoral como un todo, registran de manera más fiable las actividades complementarias de las mujeres. Además es posible que la participación de las mujeres en las actividades complementarias de la explotación haya tenido tendencia a aumentar en el curso del tiempo. Pero esta hipótesis no puede verificarse sobre la base de datos de que se dispone, que no son datos de panel.

Un segundo rasgo sobresaliente que se desprende del cuadro 12 es el aumento considerable de los activos que ejercen dos actividades complementarias durante el 
tercer trimestre, que es el trimestre en el que los trabajos agrícolas son los que demandan menos mano de obra a causa del fin de las lluvias. Este resultado sugiere una cierta estacionalidad de la agricultura, caracterizada por un número creciente de individuos que dejan completamente el trabajo en la explotación familiar para dedicar su tiempo a otras actividades durante el tercer trimestre.

Finalmente, se señalará un último resultado interesante porque es común al conjunto de fuentes utilizadas, y es que la participación de los miembros de las explotaciones agrícolas en las actividades complementarias varía poco según las regiones agroclimáticas, siendo ligeramente más marcada en la Costa.

Los datos de los cuadros 13 y 14 permiten apreciar la evolución intraanual de la distribución de las actividades complementarias según los sectores. Se observa un aumento considerable por parte de la agricultura en el tercer trimestre, mientras que el segundo y cuarto trimestres se caracterizan por una distribución considerablemente diferente de las actividades complementarias entre los sectores. La parte del comercio aparece, en promedio, tan importante como la de la agricultura, es decir, alrededor del $30 \%$ de las actividades complementarias. Si se considera sólo el subgrupo de mujeres, entonces la parte del comercio puede representar hasta el $48 \%$ de las actividades complementarias. La parte del sector de industrias manufactureras, que incluye el conjunto de las actividades artesanales, aparece relativamente estable durante el año. Se observará sin embargo un claro aumento por parte de este sector en las actividades complementarias de las mujeres durante el año.

Cuadro 13 - Distribución de los sectores de actividades complementarias.

\begin{tabular}{lrrrrrrrrr}
\hline & \multicolumn{3}{c}{ Trimestre II } & \multicolumn{4}{c}{ Trimestre III } & \multicolumn{3}{c}{ Trimestre IV } \\
\cline { 2 - 10 } & Hom. & Mujer & Total & Hom. & Mujer & Total & Hom. & Mujer & Total \\
\hline Agricultura, ganadería, caza, pesca & 36.7 & 19.4 & 30.7 & 54.8 & 38.5 & 49.0 & 38.3 & 14.9 & 28.8 \\
Explotaciones de minas y canteras & 0.2 & & 0.1 & 1.1 & & 0.7 & 0.4 & & 0.2 \\
Industrias manufactureras & 12.6 & 15.4 & 13.6 & 10.2 & 20.7 & 13.9 & 13.1 & 27.5 & 19.0 \\
Suministro de electricidad, gas y agua & & & & 0.1 & & & 0.4 & & 0.3 \\
Construcción & 6.5 & & 4.2 & 7.9 & 0.3 & 5.2 & 9.6 & & 5.7 \\
Comercio & 21.2 & 48.0 & 30.6 & 10.8 & 24.5 & 15.7 & 22.5 & 34.7 & 27.5 \\
Hoteles y restaurantes & 0.5 & 6.8 & 2.7 & 0.9 & 7.6 & 3.3 & 0.8 & 10.4 & 4.7 \\
Transporte y comunicaciones & 6.4 & & 4.1 & 5.1 & 0.1 & 3.3 & 6.3 & 0.5 & 4.0 \\
Intermediación financiera & & 0.5 & 0.2 & & & & & & \\
Actividades Inmobiliarias & 1.3 & & 0.8 & 0.4 & 0.3 & 0.4 & 1.1 & & 0.6 \\
Administración pública y defensa & 5.2 & 2.4 & 4.2 & 2.4 & 0.8 & 1.8 & 2.4 & 1.1 & 1.5 \\
Enseñanza privada & 5.0 & 2.9 & 4.2 & 3.3 & 2.6 & 3.0 & 4.0 & 6.2 & 4.2 \\
Actividades de servicios & 4.4 & 4.4 & 4.4 & 3.1 & 4.6 & 3.7 & 1.0 & 4.7 & 3.6 \\
Total & 100.0 & 100.0 & 100.0 & 100.0 & 100.0 & 100.0 & 100.0 & 100.0 & 100.0 \\
\hline
\end{tabular}

Fuente: Trimestre II: Encuesta sobre educacion, salud, empleo e ingreso, INEI, 2000.

Trimestre III: Encuesta especializada de niveles de empleo, INEI, 2000.

Trimestre IV: Encuesta sobre las condiciones de vida y pobreza, INEI, 2000. 
La distribución de las actividades complementarias según las regiones naturales del Perú confirma las escasas diferencias observadas en las fuentes utilizadas anteriormente, cualquiera que sea el trimestre del año considerado. Dos sectores concentran efectivamente del $60 \%$ al $70 \%$ de las actividades complementarias de los miembros de los hogares agrícolas, cualquiera que sea la región considerada. Estos son la agricultura y el comercio, con una preferencia marcada de los hombres por la agricultura y de las mujeres por el comercio, y las variaciones en la importancia relativa de estos dos sectores durante el año se observan uniformemente en todas las regiones.

Cuadro 14 - Distribución de los sectores de actividades complementarias por regiones.

\begin{tabular}{lrrrrrrrrrr}
\hline & \multicolumn{3}{c}{ Trimestre II } & \multicolumn{3}{c}{ Trimestre III } & \multicolumn{3}{c}{ Trimestre IV } \\
\cline { 2 - 11 } & \multicolumn{1}{c}{ Costa } & Sierra & Selva & Costa & Sierra & Selva & Costa & Sierra & Selva \\
\cline { 2 - 10 } Agricultura, ganadería, caza, pesca & 26,5 & 32,8 & 30,5 & 54,6 & 44,7 & 59,3 & 38,0 & 24,9 & 35,4 \\
Explotación de minas y canteras & & 0,2 & & 0,2 & 0,8 & 0,7 & & 0,3 & \\
Industrias manufactureras & & 13,8 & 11,7 & 12,8 & 15,4 & 9,6 & 11,3 & 21,6 & 16,2 \\
Suministro de electricidad, gas y agua & & & & & & 0,1 & & 0,1 & 1,0 \\
Construcción & 7,5 & 5,1 & & 4,4 & 6,5 & 1,4 & 4,1 & 6,9 & 2,4 \\
Comercio & 32,6 & 29,7 & 33,0 & 13,3 & 16,4 & 15,2 & 26,7 & 28,5 & 24,0 \\
Hoteles y restaurantes & 8,8 & 2,3 & 2,0 & 2,8 & 3,6 & 2,6 & 4,4 & 4,8 & 4,7 \\
Transporte y comunicaciones & 8,2 & 2,7 & 8,2 & 4,2 & 3,2 & 2,8 & 2,1 & 4,1 & 5,1 \\
Intermediación Financiera & & 0,3 & 0,1 & & & 0,1 & & & \\
Actividades Inmobiliarias & 3,9 & 0,8 & 0,1 & 0,7 & 0,3 & 0,1 & 2,8 & 0,3 & \\
Administración pública y defensa & 7,2 & 4,2 & 3,3 & 0,9 & 2,1 & 1,6 & 0,2 & 2,0 & 3,1 \\
Enseñanza & 4,1 & 4,2 & 4,5 & 1,7 & 3,3 & 3,1 & 10,0 & 3,4 & 6,3 \\
Actividades de servicios & 1,2 & 4,1 & 6,6 & 4,4 & 3,6 & 3,2 & 0,4 & 3,2 & 1,9 \\
Total & 100,0 & 100,0 & 100,0 & 100,0 & 100,0 & 100,0 & 100,0 & 100,0 & 100,0 \\
\hline
\end{tabular}

Fuente: Trimestre II: Encuesta sobre educacion, salud, empleo y ingreso, INEI, 2000.

Trimestre III: Encuesta especializada de niveles de empleo, INEI, 2000.

Trimestre IV: Encuesta sobre las condiciones de vida y pobreza, INEI, 2000.

\section{CONCLUSIÓN}

La diversificación de las fuentes de ingresos de las explotaciones agrícolas es una cuestión crucial para el bienestar de las poblaciones rurales. En un medio caracterizado por la baja productividad de la agricultura, la desocupación estacionaria, e incluso la desocupación oculta permanente, toda utilización adicional del trabajo en el medio rural puede contribuir a aumentar los ingresos, aunque sea modestamente.

Sin embargo, el conocimiento que se tiene de la situación real del empleo en el medio rural es limitado en el Perú, debido a la percepción imperfecta no sólo de las variaciones de la movilización de la mano de obra familiar para los trabajos agrícolas, sino también de la diversidad de los empleos ocupados por los miembros de las explotaciones durante un ciclo agrícola. Se habrá comprendido que presentar un cuadro completo y fiable de las actividades complementarias de los miembros de las explotaciones agrícolas es un ejercicio difícil, ya que las fuentes estadísticas son parciales, las 
metodologías de encuesta resultan finalmente poco apropiadas para esta medición, y las diferentes encuestas disponibles son difícilmente comparables. Por consiguiente, las diferentes fuentes dan como resultado una estimación variable de la importancia de estas actividades.

La principal consecuencia de los vacíos de que sufren los datos es la subestimación indudable de las actividades complementarias y por lo tanto de los ingresos que las mismas producen, sin que se pueda evaluar con precisión la importancia y el sentido del sesgo que resulta de la omisión de numerosas actividades. Se señalará simplemente que la menor omisión de estas actividades en las encuestas del INEI en comparación con las encuestas del Instituto CUÁNTO se traduce por una disminución de la importancia de la agricultura en estas actividades.

Las causas principales de estas omisiones han sido mencionadas y son, por orden de importancia, la ausencia de datos de las actividades productivas de las personas de menos de 14 años, la referencia a la semana previa a la encuesta, la poca consideración del calendario agrícola para la realización de la encuesta, y la confusión conceptual que resulta de la utilización de las nociones de ocupación principal y secundaria. La mayor parte de estos defectos podría corregirse bastante fácilmente, sin necesitar necesariamente la asignación de medios financieros adicionales exagerados.

Cuatro conclusiones principales surgen sin embargo del conjunto de los resultados presentados: la parte no desdeñable que ocupa la agricultura en el conjunto de las actividades complementarias, la concentración de estas actividades en dos o tres sectores, la relativa estabilidad de su distribución según los sectores en el tiempo y en el espacio y una división del trabajo bastante marcada entre los hombres y las mujeres.

Se puede tratar de explicar estos resultados por medio de tres argumentos: en primer lugar, la agricultura en sí es una actividad atractiva, proveedora de numerosos empleos complementarios suficientemente remunerados, lo que justifica que los individuos no busquen empleo en otro sector de actividad; en segundo lugar, las oportunidades de empleo no agrícola son escasas en las zonas rurales, y las posibilidades de empleos alternativos susceptibles de ocupar a los activos agrícolas cuando no trabajan en los campos son pocas, cualquiera que sea la región considerada; en tercer lugar, los miembros de las explotaciones agrícolas tienen dificultades para insertarse en el mercado de trabajo no agrícola, ya sea por la distancia que los separa de los empleos disponibles o por falta de las calificaciones necesarias.

Zanjar esta discusión necesitaría un análisis más detallado de los datos, lo que no es el objetivo de este artículo. Se puede sin embargo subrayar que los elementos de los que se dispone tienden a corroborar estos argumentos. Se observa una proporción ligeramente más alta de las actividades de diversificación en el sector agrícola de la zona costera donde la productividad de la agricultura y por consiguiente los ingresos agrícolas son más elevados. La importancia de los sectores del comercio y de las industrias manufactureras, que está esencialmente compuesto de actividades artesanales y de transformación de los productos agrícolas, es un indicio del bajo grado de industrialización rural y de la poca diversidad de empleos disponibles en el medio rural. Finalmente, los sectores que ofrecen empleos a los activos agrícolas peruanos son tradicionalmente sectores que absorben la mano de obra no calificada. 


\section{Referencias citadas}

CUÁNTO, 1994 - Encuesta Nacional sobre el Nivel de Vida.

COTLEAR, D., 1989 - Desarrollo campesino en los Andes, 325p.; Lima: Instituto de Estudios Peruanos.

GÖLTE, J., 1980 - La racionalidad de la organización andina, 124p.; Lima: IEP.

GONZÁLES DE OLARTE, E., 1994 - En las fronteras del mercado, 371p.; Lima: IEP.

GONZÁLES DE OLARTE, E., HOPKINS, R., KERVYN, B., ALVARADO, J. \& BARRANTES, R., 1987 - La lenta modernización de la economía campesina, 233p.; Lima: IEP.

HERRERA, J., 2002 - La pobreza en el Peru 2001, 196p.; Lima: INEI-IRD.

INEI, 1994 - Tercer Censo Nacional Agropecuario

INEI, 2000 - Encuesta Nacional de Hogares, Condiciones de Vida y Pobreza, IV trimestre.

INEI, 2000 - Encuesta Nacional de Hogares, Encuesta especializada de niveles de empleo, III trimestre.

INEI, 2000 - Encuesta Nacional de Hogares, Educación, salud, programas sociales, empleo e ingreso, II trimestre.

LEWIS, W. A., 1954 - Economic Development with Unlimited Supply of Labor, The Manchester School of Economic and Social Studies, 22(2): 139-191.

VALDIVIA, M., ROBLES, M., 1997 - Decisiones Laborales en las economías rurales del Perú, Notas para el Debate, $\mathbf{n}^{\circ}$ 14: 79-128. 